\title{
OPEN External ears for non-invasive and stable monitoring of volatile organic compounds in human blood
}

\begin{abstract}
Koji Toma $^{1}$, Shota Suzuki ${ }^{2}$, Takahiro Arakawa ${ }^{1}$, Yasuhiko Iwasaki ${ }^{3}$ \& Kohji Mitsubayashi ${ }^{1,2} \bowtie$
Volatile organic compounds (VOCs) released through skin (transcutaneous gas) has been increasing in importance for the continuous and real-time assessment of diseases or metabolisms. For stable monitoring of transcutaneous gas, finding a body part with little interference on the measurement is essential. In this study, we have investigated the possibility of external ears for stable and real-time measurement of ethanol vapour by developing a monitoring system that consisted with an overear gas collection cell and a biochemical gas sensor (bio-sniffer). The high sensitivity with the broad dynamic range ( $26 \mathrm{ppb}-554 \mathrm{ppm}$ ), the high selectivity to ethanol, and the capability of the continuous measurement of the monitoring system uncovered three important characteristics of external earderived ethanol with alcohol intake for the first time: there is little interference from sweat glands to a sensor signal at the external ear; similar temporal change in ethanol concentration to that of breath with delayed peak time (avg. $13 \mathrm{~min}$ ); relatively high concentration of ethanol relative to other parts of a body (external ear-derived ethanol:breath ethanol =1:590). These features indicated the suitability of external ears for non-invasive monitoring of blood VOCs.
\end{abstract}

Exhaled breath and transcutaneous gas contain volatile organic compounds (VOCs) from blood ${ }^{1}$. Some of these blood VOCs are resultant product of diseases or metabolisms, which has been attracting great attention to utilize these VOCs for non-invasive and simple disease screening and metabolism assessment ${ }^{2,3}$. For example, acetone is a lipid metabolite and expected for its application in lipid metabolism assessment and diabetes screening ${ }^{4}$.

Transcutaneous gas is more suitable to real-time and continuous assessment than breath due to two reasons: one is that the transcutaneous gas is released unconsciously and continuously; the other is that there is much less limitations on time and places for the collection of gas sample than breath that requires a mask or complicated procedures, such as collecting end-tidal air ${ }^{5,6}$.

There are highly sensitive analytical methods for VOCs in exhaled breath and transcutaneous gas, such as gas chromatography mass spectrometry $(\mathrm{GC}-\mathrm{MS})^{7}$, proton-transfer-reaction mass spectrometry (PTR-MS) ${ }^{8}$ that is often coupled with time of flight mass analyser (PTR-TOF-MS $)^{9}$, and selected-ion flow-tube mass spectrometry $(\text { SIFT-MS })^{10}$. Although their capability of identifying VOC composition is powerful for comprehensive analysis of the gas, the size and complexity of the system are drawbacks for monitoring transcutaneous VOC.

As simpler methodologies for blood VOCs, sensors are broadly and intensively studied from academia to industry. Lansdrop et al. developed a wristband wearable alcohol biosensor which used alcohol oxidase and Prussian Blue to measure transcutaneous blood ethanol electrochemically ${ }^{11}$. Kim et al. reported a wearable tattoo-based alcohol monitoring system which demonstrated measurement of sweat ethanol on a skin using amperometry with alcohol oxidase and Prussian Blue ${ }^{12}$. Yamada et al. presented a semiconductor-based portable sensor for transcutaneous blood acetone, which utilized zeolite to concentrate acetone before measurement ${ }^{13,14}$.

One of the biggest challenges for measurement of transcutaneous blood VOCs is its low concentration relative to breath. Generally, blood/breath alcohol concentration ratio of 2100/1 is used for legal purposes. Transcutaneous ethanol collected by Nalophan bags showed the emission rate of $48 \mathrm{ppt} /\left(\mathrm{cm}^{2} \cdot \mathrm{min}\right)$ without alcohol intake, whereas the concentration in breath was 37-207 $\mathrm{ppb}^{15,16}$. Both concentrations increase when drinking alcohol

\footnotetext{
${ }^{1}$ Department of Biomedical Devices and Instrumentation, Institute of Biomaterials and Bioengineering, Tokyo Medical and Dental University, 2-3-10 Kanda-Surugadai, Chiyoda-ku, Tokyo 101-0062, Japan. ${ }^{2}$ Graduate School of Medical and Dental Sciences, Tokyo Medical and Dental University, 1-5-45 Yushima, Bunkyo-ku, Tokyo 113-8510, Japan. ${ }^{3}$ Faculty of Chemistry, Materials and Bioengineering, Kansai University, Osaka, Tokyo 113-8668, Japan. ${ }^{\boxplus}$ email: m.bdi@tmd.ac.jp
} 
(a)

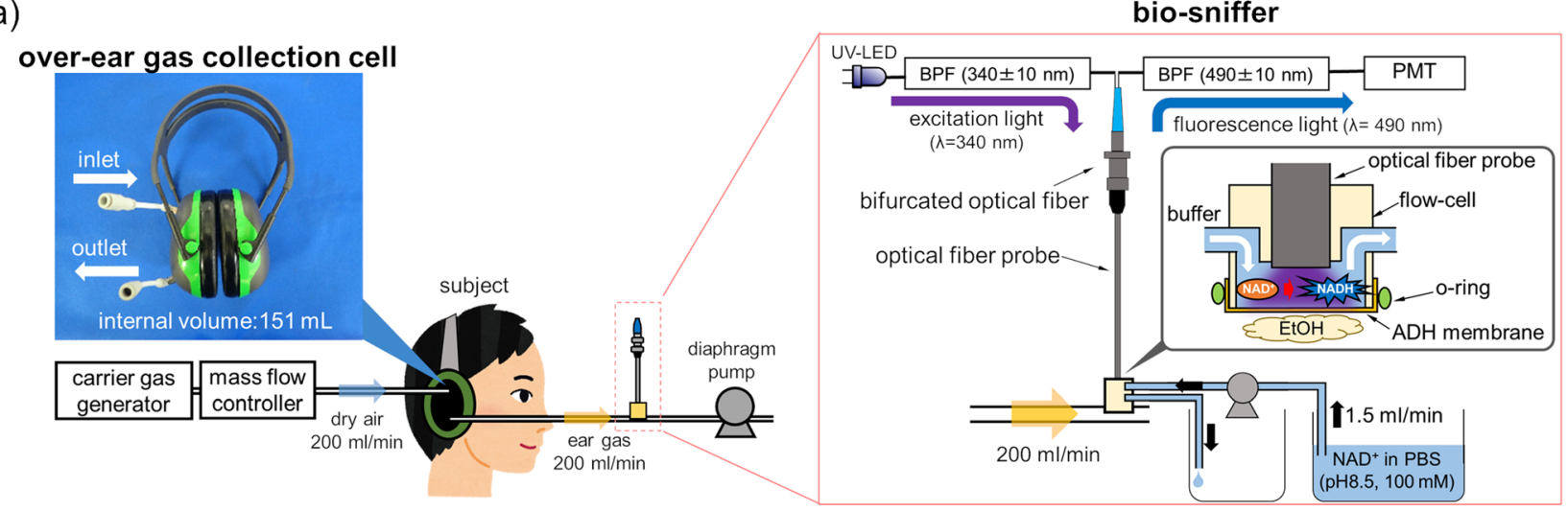

(b)

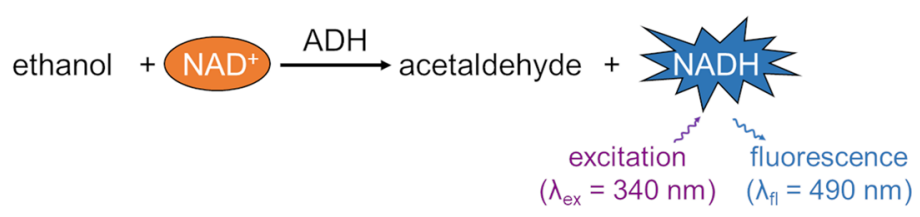

Figure 1. (a) A schematic illustration of the monitoring system for external ear-derived ethanol. The system was composed of the over-ear gas collection cell and bio-sniffer. (b) A principle of ethanol measurement using $\mathrm{ADH}$ and $\mathrm{NADH}$.

together with blood alcohol concentration. Our previous study revealed that the ethanol concentrations in transcutaneous gas from a whole hand and exhaled breath were $46 \mathrm{ppb} / \mathrm{cm}^{2}$ and $47 \mathrm{ppm}$, respectively, with alcohol intake $^{17}$. These data indicate that transcutaneous/breath ethanol concentration ratio is approximately $1 / 1000$.

Another difficulty to measure transcutaneous blood VOCs is interference by sweat and different release dynamics of the gas depending on a body part because each body part has different density of sweat glands and epidermis layers of the skin; therefore, it is important to choose a proper body region to acquire relatively high concentration of a target VOC with little interference by sweat for monitoring transcutaneous blood VOCs.

The external ear region has a skin with lower density of sweat glands $\left(140 \mathrm{spots} / \mathrm{cm}^{2}\right)$ compared to other regions of a body, such as a palm $\left(620 \mathrm{spots} / \mathrm{cm}^{2}\right)$, forearm $\left(225 \mathrm{spots} / \mathrm{cm}^{2}\right)$ and cheek $\left(360 \mathrm{spots} / \mathrm{cm}^{2}\right)^{18,19}$. In addition, Lobitz et al. reported that an external ear canal has no eccrine sweat gland ${ }^{20}$. Also, gas from the external ear is not only from an outer part of the external ear but also from the external ear canal ${ }^{21}$. It possibly causes the transcutaneous VOCs in the middle ear to be released through the tympanic membrane to the external ear canal $^{22-24}$ and the concentration of VOCs at the external ear to be high. In addition, the external ear has a relatively large space to incorporate devices to measure.

Based on the reasons above, we hypothesized that an external ear is a promising candidate for stable monitoring transcutaneous blood VOCs. To examine this hypothesis, this study began with the development of a monitoring system for external ear-derived ethanol, then the system was applied for real-time and continuous measurement of ethanol at the external ear with alcohol intake.

\section{Results and discussion}

Construction of the monitoring system. The monitoring system was developed by combining an overear gas collection cell and a gas-phase biosensor (bio-sniffer) for ethanol (Fig. 1a). The bio-sniffer measures ethanol vapor based on the principle shown in Fig. 1b. Alcohol dehydrogenase (ADH) catalyses oxidation of ethanol to produce acetaldehyde. Simultaneously, a coenzyme, oxidized form of $\beta$-nicotinamide adenine dinucleotide $\left(\mathrm{NAD}^{+}\right)$, accepts the electron to become the reduced form $(\mathrm{NADH})$ that exhibits autofluorescence $\left(\lambda_{\mathrm{ex}}=340 \mathrm{~nm}\right.$, $\lambda_{\mathrm{fl}}=490 \mathrm{~nm}$ ); therefore, ethanol can be measured by detecting the increase in the autofluorescence from NADH. An enzyme-immobilized membrane (ADH membrane) attached on the flow-cell worked as a gas-liquid diaphragm. When the ethanol vapor reaches the ADH membrane, the catalysed redox reaction occurs at the membrane together with $\mathrm{NAD}^{+}$in the buffer solution running above the membrane, which produces $\mathrm{NADH}$ in the buffer solution. Resultant NADH was excited by the UV light from the optical fiber probe, then the emitted fluorescence was collected by the same fiber probe to be detected. In the monitoring of external ear-derived gas, the sample gas from a subject was collected by the over-ear gas collection cell, then simultaneously transported to the bio-sniffer for the real-time measurement.

Characterization of ethanol bio-sniffer and over-ear gas collection cell. In order to investigate the influence of buffer solution $\mathrm{pH}$ on the activity of $\mathrm{ADH}$, four different buffer solutions, including acetate buffer $(\mathrm{AB})$, phosphate buffer $(\mathrm{PB})$, tris- $\mathrm{HCl}$ and carbonate-bicarbonate $(\mathrm{CB})$ solutions, were pumped to the flow-cell in the ethanol bio-sniffer at the flow rate of $1.5 \mathrm{~mL} / \mathrm{min}$ while measuring $1000 \mathrm{ppb}$ standard gaseous ethanol. 


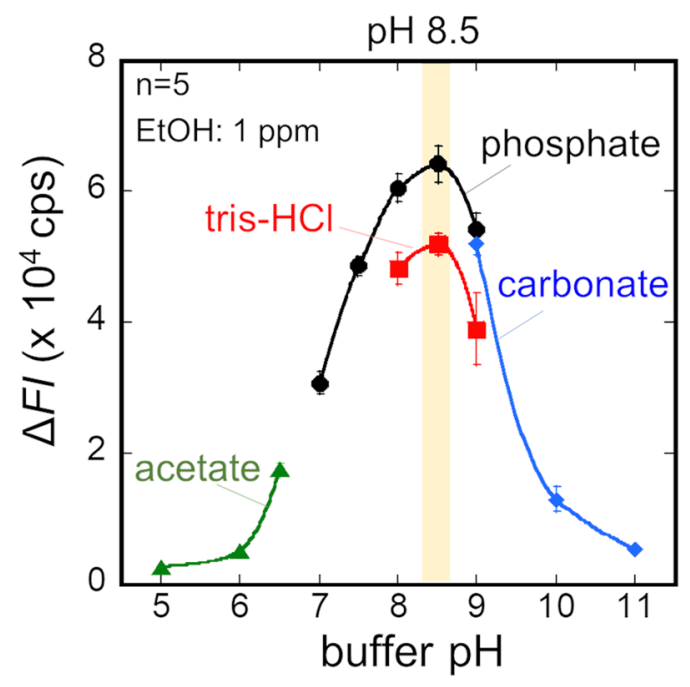

Figure 2. Influence of the buffer $\mathrm{pH}$ on the sensor output $(\Delta F I)$.
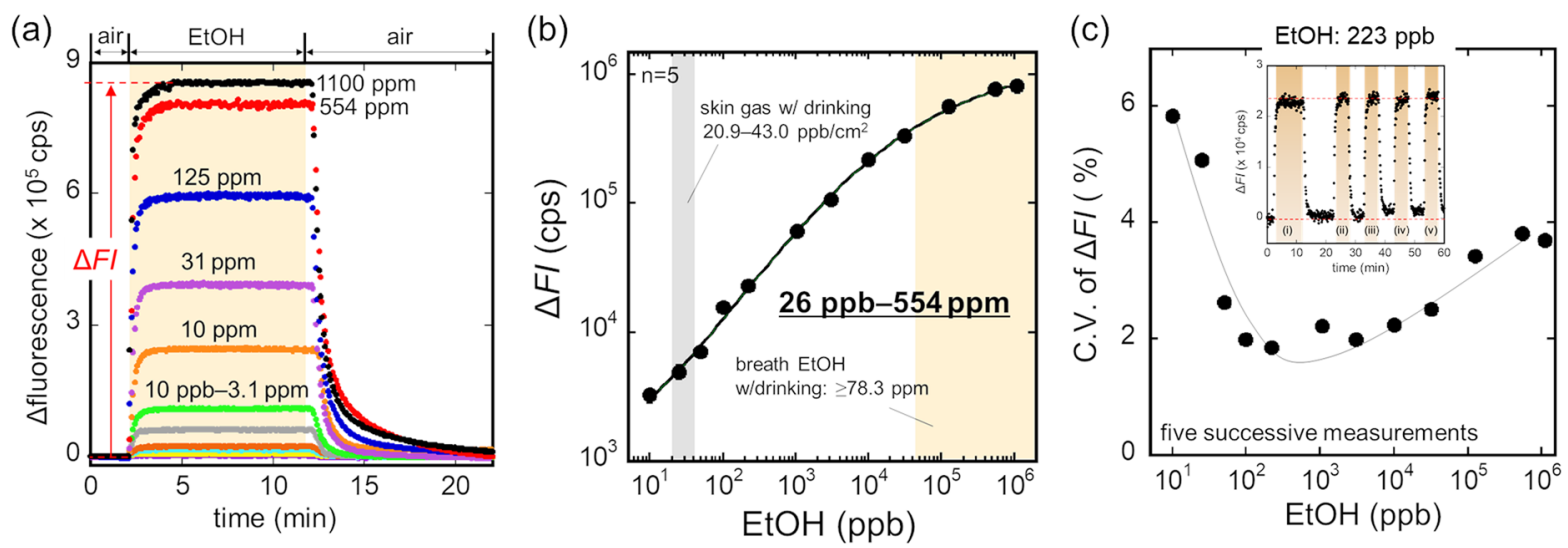

Figure 3. (a) Sensor responses to standard gaseous ethanol with various concentrations. (b) Calibration curve of the bio-sniffer to gaseous ethanol. (c) Sensor output variations in 5 repeated measurement of gaseous ethanol with different concentrations. The inset shows the sensor responses to $223 \mathrm{ppb}$ ethanol.

The fluorescence intensity increased when the gaseous ethanol was loaded to the ethanol bio-sniffer, indicating that $\mathrm{NADH}$ was produced by $\mathrm{ADH}$-catalyzed redox reaction of ethanol as described in the Fig. 1b. Then, the fluorescence intensity reached plateau under the balance between removal of produced NADH and supply of $\mathrm{NAD}^{+}$, which was controlled by the flow rate of a buffer solution. When switching the gaseous ethanol to the carrier gas, the fluorescence intensity decreased because of the termination of the ADH-catalyzed reaction and removal of NADH. Here, the sensor output $(\Delta F I)$ was defined as an increment of the fluorescence intensity from the baseline. The sensor output for each buffer solution is presented in Fig. 2. The output peaks with $\mathrm{pH} 8.5 \mathrm{~PB}$ solution. Therefore, $\mathrm{pH}$ 8.5 PB solution has used for subsequent experiments.

The sensitivity of the ethanol bio-sniffer and the reproducibility of the sensor output for various ethanol concentrations were investigated. Figure 3 a shows the sensor responses to the gaseous ethanol with the concentrations from $10 \mathrm{ppb}$ to $1100 \mathrm{ppm}$. The sensor output was dependent on the concentration of gaseous ethanol. A calibration curve in Fig. 3b shows the dynamic range of the ethanol bio-sniffer is $26 \mathrm{ppb}-554 \mathrm{ppm}$, which was determined from the intersection where ten times a standard deviation of the baseline obtained from the carrier gas equals the sensor output. The reproducibility of the sensor output during five repeated measurement of gaseous ethanol, whose concentrations correspond to those of the calibration curve, is shown in Fig. 3c.

The reproducibility was assessed for each concentration by calculating the average coefficient of variation (C.V.) of the sensor output from five trials. It shows the highest C.V. of about $4-6 \%$ at the lowest and highest concentrations, while the lowest C.V. of about $2 \%$ appeared in the middle concentration range.

The selectivity of the ethanol bio-sniffer was assessed with representative VOCs in breath, including ethanol, methanol, 1-propanol, 2-propanol, 1-butanol, formaldehyde, acetaldehyde, acetone, and 2-butanone. The concentrations of all the VOCs were fixed to be $1000 \mathrm{ppb}$. Relative sensor outputs to that from ethanol are shown in Fig. 4a. Except for 1-propanol, the relative outputs were as small as or smaller than a few per cent. Considering that breath ethanol concentration increases to about $100 \mathrm{ppm}$ when drinking alcohol, even the output from 1-propanol can be ignored because a typical concentration of 1-propanol in breath is $8.1 \mathrm{ppb}^{25}$. These results 
(a)

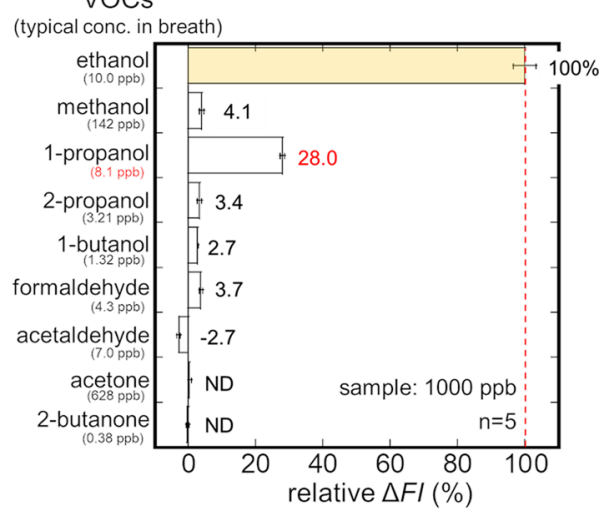

(b)

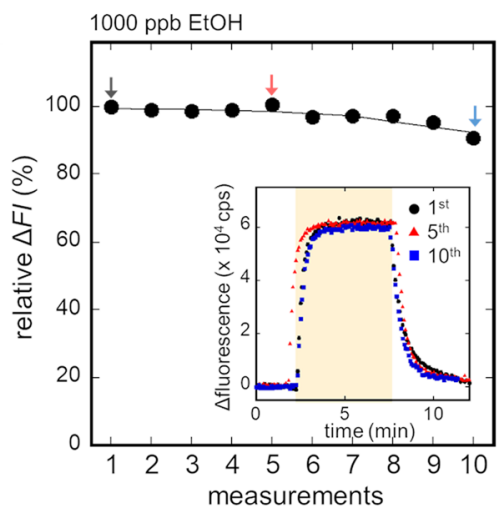

Figure 4. (a) Relative sensor output to representative VOCs in breath. (b) Relative sensor output during 10 repeated measurement of $1000 \mathrm{ppb}$ gaseous ethanol.

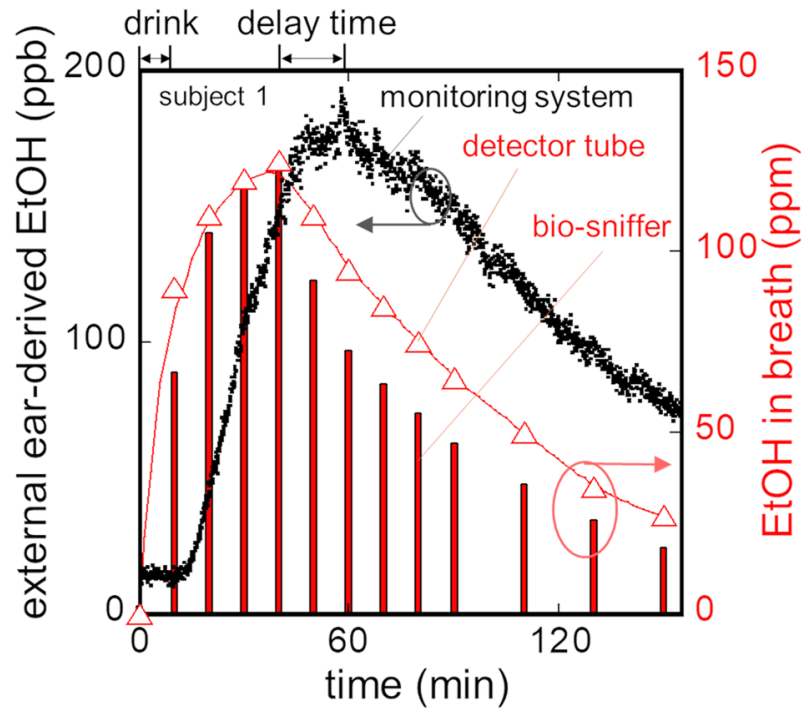

Figure 5. Monitoring of ethanol concentration after alcohol intake in the ear gas by the developed system for the subject 1 . The ethanol concentration in the ear gas $(\mathbf{O})$; in the breath measured by $(\Delta)$ detector tubes and (bars) the ethanol bio-sniffer.

supported the high selectivity of the bio-sniffer, relying on ADH specificity, to gaseous ethanol, and neglectable interference from other compounds in the gas mixture would be expected. However, there are still possibilities of interreferences which did not appear in the relative output to each compound one by one, for example unexpected inhibition or enhancement of the signal to ethanol, and they will be investigated in future study using mixed gas samples.

Presence of interferential VOCs in gas released from the over-ear gas collection cell was investigated. The gas collection cell was sealed by a polymethyl methacrylate plate. A sensor response to the gas from the collection cell exhibited no change in the fluorescence intensity when the carrier gas was exchanged to that from the gas collection cell. This result proved that no interferential VOCs are present in the gas from the over-ear gas collection cell.

The repeatability and stability of the sensor signal were also assessed by ten successive measurement of $1000 \mathrm{ppb}$ gaseous ethanol. The sensor output was not significantly degraded during 10 repeated measurements taking about 150 min (see Fig. 4b). The inset in Fig. 4b also clearly shows that the sensor responses are nicely overlapped. These results indicate that the bio-sniffer can be used in continuous measurement of gaseous ethanol.

Monitoring of external ear-derived ethanol after drinking alcohol. The developed monitoring system was applied to real-time measurement of external ear-derived ethanol. Figure 5 shows a temporal change of ethanol in the external ear gas along with that in breath measured by detector tubes (bars) and the ethanol bio-sniffer (triangles). The ethanol concentration from the external ear started to rise $7 \mathrm{~min}$ after alcohol intake 


\begin{tabular}{|l|l|l|l|l|}
\hline \multirow{2}{*}{ Subject } & \multicolumn{2}{|l|}{ Ethanol conc. (ppb) } & \multirow{2}{*}{} \\
\cline { 2 - 3 } & Ear gas & Breath & Ethanol conc. ratio (ear gas/breath) & Delay time (min) \\
\hline A & 186 & 122,000 & $1 / 650$ & 17 \\
\hline B & 116 & 98,000 & $1 / 840$ & 10 \\
\hline C & 142 & 40,000 & $1 / 280$ & 12 \\
\hline Avg. & $148 \pm 29$ & $87,000 \pm 34,422$ & $1 / 590$ & $13 \pm 3$ \\
\hline
\end{tabular}

Table 1. Comparisons of ethanol concentrations in external ear gas and breath.

and reached the peak of $183 \mathrm{ppb} 52 \mathrm{~min}$ later, then the ethanol concentration gradually decreased by alcohol metabolism. This temporal change has a similarity to that of breath ethanol concentration. Here, the validity of the breath ethanol concentrations was supported by close values and the same temporal changes obtained by two different methods. According to other reports proving that ethanol concentrations in blood and breath have a correlation, the concentration of the external ear's ethanol is most likely correlated to that in blood ${ }^{26-28}$.

Another important finding in this result was much lower noise in the signal than that from a palm ${ }^{17}$. The noise level was evaluated by a moving average and standard deviation for the change in the external ear-derived ethanol concentration over time, with $5 \mathrm{~min}$ as an interval (see Supplementary Fig. S1 online). Using these average and standard deviation, C.V. of the moving average of the ethanol concentration was also calculated. It was found the average C.V. from 0 to 90 min was of $6.9 \%$. The same analysis was conducted to the ethanol concentration from a palm presented in our previous study ${ }^{17}$, and it resulted in the C.V. of $22.7 \%$. These C.V. indicate that measuring ethanol with the external ear reduced the noise by a third compared to the palm. The reason of this low noise is assumed to be that there are few eccrine sweat glands on an external ear canal while a palm has eccrine sweat glands most densely through a body, 620 spots $/ \mathrm{cm}^{2} 18,20$. A comparison of sweat rate between a palm and external ear for another subject without alcohol is shown in Supplementary Fig. S2 online. The sweat rate of a palm $\left(171.4 \mathrm{~g} /\left(\mathrm{m}^{2} \cdot \mathrm{h}\right)\right)$ was well agreed to the reports by Park et al. $\left(109.15 \mathrm{~g} /\left(\mathrm{m}^{2} \cdot \mathrm{h}\right)\right)^{29}$ and Taylor et al. $\left(197 \mathrm{~g} /\left(\mathrm{m}^{2} \cdot \mathrm{h}\right)\right)^{19}$. The sweat rate in the external ear canal $\left(103.7 \mathrm{~g} /\left(\mathrm{m}^{2} \cdot \mathrm{h}\right)\right)$ was relatively higher than those of a wrist $\left(24.6 \mathrm{~g} /\left(\mathrm{m}^{2} \cdot \mathrm{h}\right)\right)$ and earlobe $\left(38.1 \mathrm{~g} /\left(\mathrm{m}^{2} \cdot \mathrm{h}\right)\right)$. This is perhaps due to apocrine sweat glands distributed in the outer one-third of the external ear canal ${ }^{30}$. Another reason may be connection to deeper part in the ear, which allows sweat and moisture in the deeper region to be exhaled through the external ear canal. On the other hand, the sweat rate of a palm largely fluctuates with the C.V. of 14.9\%, while that of an external ear canal was stable with the C.V. of $5.0 \%$. Since the sweat rates of the palm and wrist were similar to our previous studies, where the stability of ethanol concentrations had been influenced by the sweat rates, it was suggested that the stable ethanol concentration in Fig. 5 was related to stable sweating in the external ear canal ${ }^{17,31}$. To further reduce the noise in the external ear-derived ethanol or reduce it in the palm-derived, the shapes of collection cells may be considered in future study.

The same experiment was carried out for two other subjects. Although there were individual variations, the same trends, such as similar temporal change of ethanol concentration in the ear gas to that of breath ethanol along with delayed peak time of the ear gas from breath, were observed. A summary of ethanol concentrations in the ear gas and breath is presented in Table 1. The average peak ethanol concentrations in the ear gas and breath were $148 \pm 29 \mathrm{ppb}$ and $87 \pm 34 \mathrm{ppm}$, respectively, which leads to the concentration ratio of the ear gas to breath of 1:590. A statutory limit of breath alcohol concentration for driving in Japan is $78.3 \mathrm{ppm}$, and the breath concentration after intake of $0.6 \mathrm{~g}$ per kg body weight alcohol was $114.7 \mathrm{ppm}$ according to a study of Lindberg et al. ${ }^{27}$; they support the validity of the concentration of breath ethanol determined in this study. Our previous study revealed that the ethanol concentration from a hand (palm: $46 \mathrm{ppb} / \mathrm{cm}^{2}$; wrist: $20.9 \mathrm{ppb} / \mathrm{cm}^{2}$ ) was about 1000 -fold smaller than that in exhaled breath $(47.1 \pm 8.2 \mathrm{ppm})^{17}$. Therefore, the ethanol concentration in the ear gas is higher than the ethanol level from the hand emission. Please note that ethanol concentration of a hand was calculated by dividing the measured concentration by the area of a gas collection cell attached on a hand, while the ethanol concentration of an external ear is the total collected by the over-ear gas collection cell.

The average peak time of the external ear-derived ethanol concentration was 13 min-delayed from that in the breath. It was a similar result to other transcutaneous gases ${ }^{17,32}$. The delay was probably due to a thickness differences of layers which ethanol passes through. The thickness of a blood-air barrier of an alveolus was $2.2 \mu \mathrm{m}$ while the thickness of an external ear's epidermal layers is $69.3 \mu \mathrm{m}^{33,34}$; therefore, diffusion and transmission of VOCs from a blood vessel is slower in the ear gas.

In this study, the measurement was made in one ear which we randomly selected because it was supposed that both external ear canals were symmetric and have no differences in ethanol concentrations. However, it is also possible to measure ethanol concentrations in parallel not only in both ears but also different body parts by adding more bio-sniffers to the monitoring system.

Conventionally, ethanol, particularly in exhaled breath, is measured by colorimetry, infrared (IR) spectroscopy, and fuel cell technology. These methodologies have been already implemented in products and used in practice $^{35}$. However, there is an interference problem from other alcohols. For example, Laakso et al. studied the interference from solvents on ethanol analysis by an IR spectroscopy-based evidential breath analyser. Their study revealed that ketones, diethyl ether and ethyl acetate did not interfere with breath ethanol measurement, but 1-propanol and 2-propanol had a significant influence on the ethanol measurement ${ }^{36}$. Our sensor, on the other hand, relies on an enzyme that has high specificity to a substrate. Therefore, as presented in Fig. 4a, there is no significant interference from other alcohols. In addition, the capability of continuous measurement is suitable 
for the monitoring. These two unique properties of our monitoring system enabled us to explore the possibility of external ears for blood VOC monitoring.

In this study, ethanol was selected as a model target VOC, but principally this system is applicable to other VOCs by changing an enzyme in the bio-sniffer. Therefore, in future, the monitoring system will be applied to metabolisms assessment and disease screening that require detailed and real-time temporal information.

\section{Conclusion}

We have examined the possibility of the external ear for stable monitoring of transcutaneous VOC by developing the monitoring system. The monitoring system comprises of the over-ear gas collection cell and the ethanol bio-sniffer and allowed for real-time and continuous measurement of temporal change in ethanol concentration of the ear gas after alcohol intake. This monitoring uncovered three important characteristics of the ear-derived ethanol for the first time: little interference from sweat to the sensor signal; higher ethanol concentration than that from a hand; similar temporal change to the breath with delayed peak time. These findings suggest the suitability of the external ear for blood ethanol monitoring. The monitoring system is potentially applicable to other VOCs b changing an enzyme. Using this versatility, we will further investigate external ear-derived VOCs for non-invasive and real-time assessment of metabolisms and disease screening.

\section{Methods}

Materials. $\mathrm{ADH}$ (activity of $128 \mathrm{unit} / \mathrm{mg}$ ), and oxidized form of $\beta$-nicotinamide adenine dinucleotide $\left(\mathrm{NAD}^{+}\right)$were purchased from Oriental Yeast (Japan). A hydrophilic polytetrafluoroethylene (H-PTFE) membrane (thickness of $80 \mu \mathrm{m}$, porosity of $80 \%$, pore size of $0.2 \mu \mathrm{m}$ ) used for an enzyme membrane was from Millipore (USA). A polymer entrapping $\mathrm{ADH}$ in the membrane, poly[2-methacryloyloxyethyl phosphorylcholine (MPC)-co-2-ethylhexyl methacrylate (EHMA)] (PMEH), was synthesized in house by free radical-polymerization method ${ }^{37}$.

All the chemicals to prepare the following three different buffer solutions were from Fujifilm Wako Pure Chemical (Japan). PB solution (100 mM, pH 8.0) was prepared by adding potassium dihydrogen phosphate solution ( $100 \mathrm{mM}$ in ultrapure water) to disodium hydrogen phosphate solution (100 $\mathrm{mM}$ in ultrapure water) to buffer the solution $\mathrm{pH}$ to 8.0 . AB solution $(100 \mathrm{mM}$ ) was prepared by adding $100 \mathrm{mM}$ sodium acetate solution to $100 \mathrm{mM}$ acetic acid solution to buffer the $\mathrm{pH}$ to $5.0-6.5$. Tris- $\mathrm{HCl}$ solution $(100 \mathrm{mM})$ was prepared to add $\mathrm{HCl}$ solution to $100 \mathrm{mM}$ trimethylolaminomethane solution to buffer the $\mathrm{pH}$ to 8.0-9.0. $100 \mathrm{mM} \mathrm{CB}$ solution $(100 \mathrm{mM})$ was prepared to add $100 \mathrm{mM}$ sodium carbonate solution to sodium hydrogen carbonate solution to buffer $\mathrm{pH}$ to $9.0-11.0$.

Construction of ethanol bio-sniffer. The bio-sniffer was composed of excitation and detection units which were connected to a bifurcated optical fibre (PVSMA2-2 STU600-STUH190S, one fibre with the core diameter of $600 \mu \mathrm{m}$ for fluorescence surrounded by 35 fibres with the core diameter of $190 \mu \mathrm{m}$ for ultraviolet light, Mitsubishi Cable Industries, Japan). The excitation unit has a UV light emitting diode (UV-LED, centre wavelength $=340 \mathrm{~nm}, 340-\mathrm{FL}-01-G 01$, DOWA, Japan) and a bandpass filter (BPF, $\lambda=340 \pm 10 \mathrm{~nm}$, LX0340, Asahi Spectra, Japan) to make the peak wavelength of the excitation light $340 \mathrm{~nm}$. The detection unit has a photomultiplier tube (PMT, H7421-40, Hamamatsu Photonics, Japan) and another BPF ( $\lambda=490 \pm 10 \mathrm{~nm}$, MX0490, Asahi Spectra, Japan) to extract fluorescence light from NADH. A flow-cell made of polymethyl methacrylate is attached to an optical fibre probe end (F1000-ANGLE90, Ocean Optics, USA), that is connected to the bifurcated optical fibre. ADH membrane was attached and fixed at the end of the flow-cell by an o-ring to work as a gas-liquid diaphragm.

The $\mathrm{ADH}$ membrane was prepared as follows: $\mathrm{ADH}$ was dissolved in $\mathrm{PB}(\mathrm{pH} 8.0,80 \mathrm{mM})$ to prepare $4.7 \%$ (w/v) ADH solution; a 15\% (w/w) PMEH solution was prepared using ethanol; a mixed solution $\left(60 \mathrm{units} / \mathrm{cm}^{2}\right)$ of the ADH and PMEH solutions at the same volume ratio was spread over the $2 \times 2 \mathrm{~cm}^{2} \mathrm{H}-\mathrm{PTFE}$ membrane; the coated PTFE membrane was dried for $3 \mathrm{~h}$ followed by rinsing with PB.

Fabrication of over-ear gas collection cell for external ear's transcutaneous ethanol. An overear gas collection cell was fabricated by modifying a commercial earmuff (X1A, $3 \mathrm{M}$ ) which has cups made of acrylonitrile-styrene-acrylate resin and urethane cushions covered by polyvinyl chloride sheets. Two connectors with the inner diameter of $4 \mathrm{~mm}$ were attached to the holes made on the earmuff cups. These holes were used as an inlet for a filtered air (carrier gas) and an outlet for sample gas containing ear gas, respectively (Fig. 1a). The internal volume of the cup is $151 \mathrm{~mL}$.

Monitoring of external ear-derived ethanol after alcohol intake. Real-time and continuous measurement of external ear-derived ethanol was conducted for three healthy male subjects with alcohol intake. This experiment was approved by the ethics committee of Faculty of Medicine, Tokyo Medical and Dental University (approval number: M2018-160) and performed in accordance with the guidelines and regulations after informed consent had been obtained from all subjects. The subjects did not take any alcohol and drugs for $72 \mathrm{~h}$ before the experiment.

The carrier gas from a compressor flew into the collection cell attached on a subject's ear at the flow rate of $200 \mathrm{~mL} / \mathrm{min}$ and was pumped out with the same flow rate by a diaphragm pump located behind the bio-sniffer in order to make the internal pressure of the cell unchanged. The side of the ear being measured was randomly selected. 
Firstly, base ethanol concentration in the external ear gas was measured for 10 min without drinking alcohol. Then, a subject drank alcohol at the concentration of $0.4 \mathrm{~g}$ per $\mathrm{kg}$ body weight within $5 \mathrm{~min}$, and the measurement continued for another $140 \mathrm{~min}$.

For comparisons, ethanol concentrations in breath were also simultaneously but intermittently measured by detector tubes (GASTEC, accuracy: C.V. of $10 \%$ for 100 to $500 \mathrm{ppm}$, Japan) and the ethanol bio-sniffer. The endexpiratory sampling method was employed to collect breath samples. In the method, a subject inhaled deeply though the nose and paused for $10 \mathrm{~s}$; then, the subject exhaled through the mouth gently for $3 \mathrm{~s}$ to exclude the dead space followed by breathing into a gas sampling bag with the volume of $3 \mathrm{~L}$. The inside of the gas sampling bag was fluorine-coated to prevent adsorption of breath components.

Sweat rate measurement. This experiment was approved by the ethics committee of Faculty of Medicine, Tokyo Medical and Dental University (approval number: M2018-160) and performed in accordance with the guidelines and regulations after informed consent had been obtained from a subject. Sweat rates of four different parts (palm, wrist, external ear canal, and earlobe) were measured with a ventilated capsule-type perspiration meter (SKN-2000, Nishizawa Electric Meters Manufacturing, Japan). A capsule of the perspiration meter was attached on a skin surface, and the sweat rate was measured for $5 \mathrm{~min}$ at room temperature. A male subject who had fasted for $6 \mathrm{~h}$ and had not consumed alcohol was at rest during the measurement.

Received: 11 December 2020; Accepted: 27 April 2021

Published online: 10 June 2021

\section{References}

1. Amann, A. et al. The human volatilome: volatile organic compounds (VOCs) in exhaled breath, skin emanations, urine, feces and saliva. J. Breath Res. 8, 034001 (2014).

2. Buszewski, B. et al. Detection of volatile organic compounds as biomarkers in breath analysis by different analytical techniques. Bioanalysis 5, 2287-2306 (2013).

3. Jalal, A. H. et al. Prospects and challenges of volatile organic compound sensors in human healthcare. ACS Sensors 3, 1246-1263 (2018).

4. Španěl, P., Dryahina, K., Rejšková, A., Chippendale, T. W. E. \& Smith, D. Breath acetone concentration; biological variability and the influence of diet. Physiol. Meas. 32, N23-N31 (2011).

5. Prado, C., Marín, P. \& Periago, J. F. Application of solid-phase microextraction and gas chromatography-mass spectrometry to the determination of volatile organic compounds in end-exhaled breath samples. J. Chromatogr. A 1011, 125-134 (2003).

6. Nose, K. et al. Identification of ammonia in gas emanated from human skin and its correlation with that in blood. Anal. Sci. 21, 1471-1474 (2005).

7. Tsuda, T., Ohkuwa, T. \& Itoh, H. Findings of skin gases and their possibilities in healthcare monitoring. in Gas Biology Research in Clinical Practice 125-132 (KARGER, 2011). doi:https://doi.org/10.1159/000321953.

8. Bajtarevic, A. et al. Noninvasive detection of lung cancer by analysis of exhaled breath. BMC Cancer 9, 348 (2009).

9. Herbig, J. et al. On-line breath analysis with PTR-TOF. J. Breath Res. 3, 027004 (2009).

10. Turner, C., Španěl, P. \& Smith, D. A longitudinal study of methanol in the exhaled breath of 30 healthy volunteers using selected ion flow tube mass spectrometry, SIFT-MS. Physiol. Meas. 27, 637-648 (2006).

11. Lansdorp, B., Ramsay, W., Hamid, R. \& Strenk, E. Wearable enzymatic alcohol biosensor. Sensors (Switzerland) 19, 2380 (2019).

12. Kim, J. et al. Noninvasive alcohol monitoring using a wearable tattoo-based iontophoretic-biosensing system. ACS Sens. 1, 10111019 (2016).

13. Yamada, Y., Hiyama, S., Toyooka, T., Onoe, H. \& Takeuchi, S. Skin-emitted acetone detection toward self-monitoring of fat metabolisms. in 17th International Conference on Miniaturized Systems for Chemistry and Life Sciences, MicroTAS 2013 vol. $31842-1844$ (2013).

14. Yamada, Y. et al. Ultratrace measurement of acetone from skin using zeolite: toward development of a wearable monitor of fat metabolism. Anal. Chem. 87, 7588-7594 (2015).

15. Mochalski, P., King, J., Unterkofler, K., Hinterhuber, H. \& Amann, A. Emission rates of selected volatile organic compounds from skin of healthy volunteers. J. Chromatogr. B Anal. Technol. Biomed. Life Sci. 959, 62-70 (2014).

16. Fenske, J. D. \& Paulson, S. E. Human breath emissions of VOCs. J. Air Waste Manag. Assoc. 49, 594-598 (1999).

17. Arakawa, T. et al. Real-time monitoring of skin ethanol gas by a high-sensitivity gas phase biosensor (bio-sniffer) for the noninvasive evaluation of volatile blood compounds. Biosens. Bioelectron. 129, 245-253 (2019).

18. Wilke, K., Martin, A., Terstegen, L. \& Biel, S. S. A short history of sweat gland biology. Int. J. Cosmet. Sci. 29, 169-179 (2007).

19. Taylor, N. A. S. A. \& Machado-Moreira, C. A. Regional variations in transepidermal water loss, eccrine sweat gland density, sweat secretion rates and electrolyte composition in resting and exercising humans. Extreme Physiol. Med. 2, 4 (2013).

20. Lobitz, W. C. \& Campbell, C. J. Physiology of the glands of the human ear canal: preliminary report. J. Investig. Dermatol. 19, 125-135 (1952).

21. Anthwal, N. \& Thompson, H. The development of the mammalian outer and middle ear. J. Anat. 228, 217-232 (2016).

22. Hergils, L. \& Magnuson, B. Human middle ear gas composition studied by mass spectrometry. Acta Otolaryngol. 110, 92-99 (1990).

23. Takahashi, H. et al. Assessment of the gas exchange function of the middle ear using nitrous oxide a preliminary study. Acta Otolaryngol. 114, 643-646 (1994).

24. Yuksel, S., Swarts, J. D., Banks, J., Seroky, J. T. \& Doyle, W. J. In vivo measurement of $\mathrm{O}_{2}$ and $\mathrm{CO}_{2}$ gas exchange across the human tympanic membrane. Acta Otolaryngol. 129, 716-725 (2009).

25. Van den Velde, S., Nevens, F., Van Hee, P., Van Steenberghe, D. \& Quirynen, M. GC-MS analysis of breath odor compounds in liver patients. J. Chromatogr. B Anal. Technol. Biomed. Life Sci. 875, 344-348 (2008).

26. Modun, D., Vuković, J., Sutlović, D., Budimir, D. \& Boban, M. Comparison of breath and blood alcohol concentrations in a controlled drinking study. Period. Biol. 3, 132 (2010).

27. Lindberg, L. et al. Breath alcohol concentration determined with a new analyzer using free exhalation predicts almost precisely the arterial blood alcohol concentration. Forensic Sci. Int. 168, 200-207 (2007).

28. Jones, A. W. \& Andersson, L. Comparison of ethanol concentrations in venous blood and end-expired breath during a controlled drinking study. Forensic Sci. Int. 132, 18-25 (2003).

29. Park, S. J. \& Tamura, T. Distribution of evaporation rate on human body surface. Ann. Physiol. Anthropol. 11, 593-609 (1992).

30. Thompson, L. D. R., Nelson, B. L. \& Barnes, E. L. Ceruminous adenomas. Am. J. Surg. Pathol. 28, 308-318 (2004). 
31. Iitani, K., Naisierding, M., Toma, K., Arakawa, T. \& Mitsubayashi, K. Evaluation for regional difference of skin-gas ethanol and sweat rate using alcohol dehydrogenase-mediated fluorometric gas-imaging system (sniff-cam). Analyst 145, 2915-2924 (2020).

32. Lawson, B. et al. Transdermal alcohol measurements using MOX sensors in clinical trials. Proceedings 1, 431 (2017).

33. Gehr, P., Bachofen, M. \& Weibel, E. R. The normal human lung: ultrastructure and morphometric estimation of diffusion capacity. Respir. Physiol. 32, 121-140 (1978).

34. Lee, Y. \& Hwang, K. Skin thickness of Korean adults. Surg. Radiol. Anat. 24, 183-189 (2002).

35. Dasgupta, A. Measurement of alcohol levels in body fluids and transdermal alcohol sensors. in Alcohol and its Biomarkers 65-90 (Elsevier, 2015). doi:https://doi.org/10.1016/B978-0-12-800339-8.00003-1.

36. Laakso, O., Pennanen, T., Himberg, K., Kuitunen, T. \& Himberg, J.-J. Effect of eight solvents on ethanol analysis by Dräger 7110 evidential breath analyzer. J. Forensic Sci. 49, 1-4 (2004).

37. Kudo, H. et al. Glucose sensor using a phospholipid polymer-based enzyme immobilization method. Anal. Bioanal. Chem. 391, 1269-1274 (2008).

\section{Acknowledgements}

This work was partly supported by Japan Society for the Promotion of Science (JSPS, Japan) KAKENHI Grant Number JP 17H01759, 16KK0143 and 15H04013; a grant from Japan IDDM network; the Ministry of Education, Culture, Sports, Science and Technology (MEXT, Japan) Special Funds for "Cooperative Research Project of Research Center for Biomedical Engineering".

\section{Author contributions}

K.T., S.S., T.A. and K.M. carried out the measurements, analyzed the results, and wrote the main manuscript text; S.S. and T.A. designed the experimental setup; Y.I. synthesized the polymer; K.M. commented on the setup and initiated the project; all authors participated in discussions over the results and revised the manuscript.

\section{Competing interests}

The authors declare no competing interests.

\section{Additional information}

Supplementary Information The online version contains supplementary material available at https://doi.org/ 10.1038/s41598-021-90146-1.

Correspondence and requests for materials should be addressed to K.M.

Reprints and permissions information is available at www.nature.com/reprints.

Publisher's note Springer Nature remains neutral with regard to jurisdictional claims in published maps and institutional affiliations.

(c) (i) Open Access This article is licensed under a Creative Commons Attribution 4.0 International License, which permits use, sharing, adaptation, distribution and reproduction in any medium or format, as long as you give appropriate credit to the original author(s) and the source, provide a link to the Creative Commons licence, and indicate if changes were made. The images or other third party material in this article are included in the article's Creative Commons licence, unless indicated otherwise in a credit line to the material. If material is not included in the article's Creative Commons licence and your intended use is not permitted by statutory regulation or exceeds the permitted use, you will need to obtain permission directly from the copyright holder. To view a copy of this licence, visit http://creativecommons.org/licenses/by/4.0/.

(C) The Author(s) 2021 